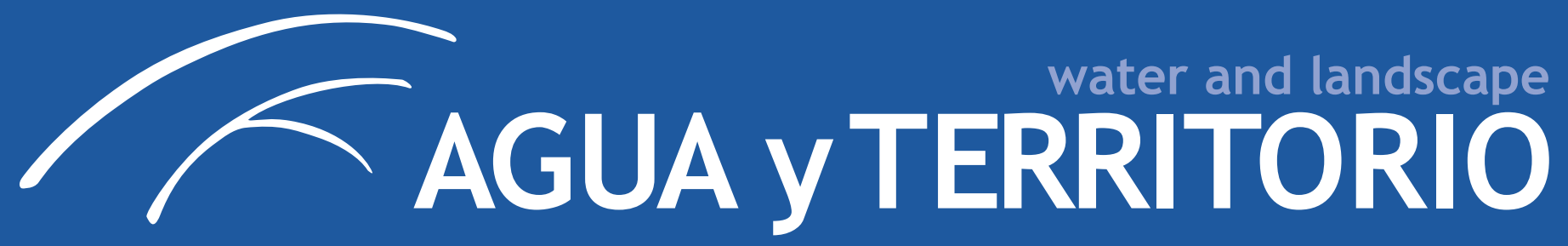

\title{
Agua urbana: Mercantilización y resistencia social en España
}

\author{
Urban Water: Commodification and Social Resistance in Spain
}

Luis Babiano-Amelibia

Asociación Española de Operadores Públicos de Abastecimiento y Saneamiento (AEOPAS). Sevilla, España. luis.babiano@gmail.com

Resumen - El debate entre la gestión pública y la privada de los servicios urbanos de agua se centra en la batalla ideológica de las distintas opciones políticas. En España se ha ido configurando en los últimos treinta años un marco propicio al proceso privatizador. Esta tendencia se ha reforzado recientemente como consecuencia de la reorientación estratégica de las multinacionales del agua hacia los mercados maduros y el inadecuado uso del canon concesional por parte de los municipios. Sin embargo, con el inicio de la actual crisis económica se han multiplicado los movimientos de resistencia ciudadana frente a este proceso. Más allá de los éxitos relativos conseguidos por las movilizaciones ciudadanas, sólo una correcta armonización entre las reformas legislativas y la movilización popular puede revertir la tendencia privatizadora.

Abstract - The debate between public and private management of urban water services focuses on the ideological battle of the different policy options. Spain has experienced conditions favorable to the privatization process over the past thirty years. Recently this trend has been reinforced by the strategic reorientation of the multinational water companies towards mature markets and the improper use of concession fees by the municipalities. The lack of municipal resources, the central administration's imposition of austerity and reform programs on local governments and the weaknesses of regulation have reinforced that trend. The Spanish model of privatizing urban water management is costly for the citizen: it increases water rates; it is environmentally unsustainable; because increased water consumption benefits businesses the most, transparency is dispensed with as there are no regulatory bodies or indicators of management quality and reliable statistics; it is exclusive, since it endangers the water access of many vulnerable groups; and it causes a real loss of control when the authorities in charge are sometimes forced to renew the services without competitive bidding. For all these reasons, the current process of water management privatization in Spain is also triggering a social movement of resistance to confront the commodification of this vital resource. Beyond the relative success achieved by citizen protests, only by harmonizing the interests of legislative reformers and citizen advocates can the trend towards privatization be reversed. It is necessary to establish a broad consensus through a public water agreement to achieve economic, social and environmental sustainability.

Palabras clave: agua urbana; privatización de la gestión; remunicipalización; movimientos ciudadanos; España Keywords: urban water; privatization of public services; redistricting; popular mobilization; Spain

Información Artículo: Recibido: 19 enero 2015

Revisado: 14 febrero 2015

Aceptado: 26 junio 2015

Código JEL: H12, H41, L38, L95

(c) Universidad de Jaén / Seminario Permanente Agua, Territorio y Medio Ambiente (CSIC) 


\section{INTRODUCCIÓN}

En la mayoría de los países miembros de la Unión Europea la gestión de los servicios de abastecimiento de agua urbana, alcantarillado y depuración de aguas residuales se realiza a nivel local, principalmente por los municipios ${ }^{1}$, al entender que esta es la mejor forma de garantizar el acceso ciudadano a un bien esencial. Sin embargo, en ocasiones, las instalaciones de abastecimiento y depuración superan el ámbito municipal -embalses, estaciones de tratamiento 0 depuradoras-; o bien, con objeto de aprovechar las economías de escala, se propicia la prestación del servicio a través de entidades supramunicipales, que no dejan de ser administraciones públicas locales.

En el ámbito español la normativa ${ }^{2}$ no obliga a que sea la propia entidad local la que preste los servicios urbanos de agua de forma directa, sino que la gestión del ciclo urbano del agua se puede también realizar de forma mancomunada, consorciada 0 delegándola a una empresa pública, privada o mixta ${ }^{3}$. Así, en las últimas tres décadas se ha configurado en España una estructura heterogénea de modelos de gestión del ciclo urbano del agua.

A la gran cantidad de municipios que ejercen con autonomía sus competencias en esta materia se ha unido un número creciente de consistorios que han ido delegando esas responsabilidades de gestión en empresas privadas ${ }^{4}$. Este proceso de privatización se ha producido en una situación de carencia de información y de ausencia total de participación social. Sin embargo, en la actualidad, aún existe un importante número de empresas públicas, como el Consorcio de Aguas de Gipuzkoa, la Empresa Municipal de Aguas de Córdoba (EMACSA), la Empresa Municipal de Aguas de Málaga (EMASA), la Empresa Metropolitana de Abastecimiento y Saneamiento de Aguas de Sevilla (EMASESA), Agua y Residuos del Campo de Gibraltar (ARCGISA), Aguas del Huesna, la Empresa Municipal de Aguas de La Coruña (EMALCSA) y otras más, que son garantía de disfrute del derecho humano al agua frente a otros tipos de gestión basados en la obtención de beneficios a corto plazo.

El debate entre la gestión pública y la privada se centra en la batalla ideológica de las distintas opciones políticas. Sin embargo, el informe de fiscalización del Sector Público Local de 20115, realizado por el Tribunal de Cuentas, concluye que para los municipios de menos de 20.000 habitantes -el 95\% del total de municipios españoles- la gestión pública directa de servicios básicos como el abastecimiento domiciliario de agua potable, la limpieza viaria y la recogida de residuos sólidos urbanos tienen un coste menor que con la externalización de dichos servicios.

Los resultados del anterior informe están en línea con los obtenidos en el estudio que se realizó anteriormente desde el Departamento de Economía Aplicada de la Facultad de Ciencias Económicas y Empresariales de la Universidad de Granada 6 dirigido a municipios de mayor dimensión. Dicho estudio compara la

\footnotetext{
1 UrbanWater FP7 Project, 2014; OECD, 2004.

2 Art. 85 de la ley 7/1985, de 2 de abril, Reguladora de las Bases del Régimen Local.

3 González-Gómez, García-Rubio, y Guardiola, 2012.

4 González-Gómez, García-Rubio, y González-Martínez, 2014.

5 Tribunal de Cuentas, 2013.

6 García-Rubio, González-Gómez, y Guardiola, 2009.
}

eficiencia de una muestra de empresas públicas y privadas andaluzas que prestan el servicio de abastecimiento urbano de aguas en los principales núcleos y aglomeraciones urbanas de la región, cubriendo a cerca del $50 \%$ de la población andaluza. El estudio concluye que las empresas públicas son más eficientes que las privadas en la prestación del servicio, y considera que uno de los motivos es la laxitud en el control de la actividad del operador privado por parte de la Administración.

A la vista de estos resultados, cabría preguntarse a qué otros intereses, que no sea la eficiencia en la gestión, obedece el proceso privatizador del servicio de agua vivido en España en los últimos años. Se puede decir sin temor a equivocarse que detrás de cada proceso de privatización hay una necesidad de financiación por parte de la entidad privatizadora ${ }^{7}$.

Nuestro artículo se estructura del siguiente modo. En la siguiente sección se describen brevemente las causas principales de las recientes privatizaciones en el sector del agua urbana en España y sus consecuencias. Después se analiza la evolución del modelo privatizador español y el previsible impacto en las entidades públicas locales de las últimas reformas legislativas. El artículo continúa presentando los rasgos más destacados de los movimientos sociales españoles en contra de la privatización de la gestión, prestando especial interés a los recientes casos del Canal de Isabel II en Madrid y de Alcázar de San Juan. Para finalizar, se presentan algunas conclusiones.

\section{La burbuja del agua en España y sus consecuencias}

La fórmula de privatización más utilizada en España es la concesión de los servicios a una empresa privada ${ }^{8}$. El agua sigue siendo pública y el servicio competencia y responsabilidad de las entidades locales, pero la gestión se adjudica a un agente privado. Sin embargo, en todos los casos de privatización del ciclo urbano del agua, la empresa privada paga a la entidad local una suma de dinero a cambio de la concesión que se denomina "canon concesional". Estos cánones concesionales millonarios, lejos de mejorar las infraestructuras hidráulicas, se dedican a aliviar las difíciles finanzas municipales y son repercutidos en tarifa a los usuarios sin que aparezcan claramente reflejados en ella.

Para abonar el canon concesional las empresas privadas recurren al crédito, que obtienen con el respaldo de las tarifas de los más de veinte años que suele durar la concesión, y con la garantía de un porcentaje de deudores fallidos inferior al $5 \%$. Es decir, dos décadas de ingresos permanentes y asegurados ya que se trata de un mercado cautivo prestado en régimen de monopolio con pagos garantizados por la amenaza del corte de suministro. El agua en España es un refugio financiero y es la ciudadanía quien paga esos créditos con su correspondiente interés y beneficio empresarial.

Así se ha llegado a una situación en la que la gestión priva$\mathrm{da}$, a través de empresas mixtas o privadas, abastece ya al $55 \%$ del total de la población española9. A su vez, esa gestión privada

\footnotetext{
7 Biswas, 2006. Bel y Fageda, 2007, 2009. Varis, Biswas, Tortajada, y Lundqvist, 2006.

8 AEAS, 2012

9 González-Gómez, García-Rubio, y González-Martínez, 2014.
} 
está controlada en un $87 \%$ por dos empresas: Aguas de Barcelona (AGBAR) -perteneciente al grupo Suez Environnement- y Aqualia -perteneciente al grupo Fomento de Construcciones y Contratas-. Así pues, en la práctica, se puede decir que se está gestionando un derecho humano en un régimen de auténtico oligopolio donde no hay auténtica competencia.

Este modelo de gestión es costoso para el ciudadano, que ve incrementada su tarifa; medioambientalmente insostenible, pues a mayor consumo de agua, mayor es el beneficio empresarial -como ponen en evidencia las quejas de AGBAR por el descenso en el consumo durante la sequía que sufrió Cataluña en 2007-; escasamente transparente, pues no existen órganos reguladores ni indicadores de calidad de gestión ni estadísticas fiables; excluyente, en cuanto pone en peligro el acceso al agua a muchos colectivos vulnerables (ver Anexo I) y provoca una auténtica pérdida del control de las administraciones, que a veces se ven abocadas a renovar los servicios sin licitación pública.

Los efectos no deseados de la privatización han hecho que en muchas ciudades europeas como Grenoble, París o Berlín se haya remunicipalizado recientemente el servicio. En la capital francesa durante el primer año de gestión pública bajaron un $8 \%$ las tarifas y se ganaron 35 millones ${ }^{10}$. En París no hay cortes de agua porque una familia no pueda pagar. Hay una ayuda social y, si no es suficiente, un fondo de solidaridad de la empresa pública para hacer frente al consumo mínimo vital. La gestión pública ha hecho que todo el beneficio económico se reinvierta en el servicio y se ha implantado una política innovadora de protección del medio ambiente. Se han creado nuevos servicios, como el de control de fugas, y se ha logrado que con la empresa pública haya una gestión mucho más democrática y participativa: personal, usuarios y asociaciones ciudadanas están en el consejo de administración.

Mientras tanto, España camina en dirección opuesta ${ }^{11}$ y el proceso de privatización -y de falta de transparencia en la gestión- se ve favorecido por la falta de recursos municipales, por los programas de austeridad y de reforma de la administración local impuestos por el gobierno central y por la debilidad de la regulación. Así, se ha privatizado la gestión del agua en una parte considerable del territorio.

\section{El DERECHO “público" subordinado al "MERCANTIL"}

Hasta mediados del siglo XIX en España los servicios públicos sociales -sanidad, beneficencia, asistencia social, educación, abastecimiento de agua - eran actividades asumidas por la sociedad aunque estuvieran reguladas por el Estado. El individualismo liberal dejó al ciudadano solo ante el Estado y este se encontró con la necesidad de asumir muchas de esas tareas abandonadas por los antiguos gestores y declararlas como propias ${ }^{12}$. La Revolución Industrial, los avances técnicos y las medidas higienistas tra-

\footnotetext{
10 Pigeon, 2013.

11 En 2006 la empresa pública suministraba el servicio de abastecimiento urbano de agua al 43\% de la población, mientras que en 2012 este porcentaje se ha reducido al $39 \%$. En el mismo periodo la empresa privada ha pasado del $33 \%$ al $36 \%$, y la empresa mixta del $8 \%$ al $13 \%$ (AEAS, 2006, 2012).

12 Matés Barco, 2008.
}

jeron consigo los primeros pasos en la creación de lo que podemos denominar abastecimientos de agua "modernos".

No obstante, la creación de estos nuevos sistemas recayó sobre los ayuntamientos - salvo en el caso de Madrid que fue asumido por el estado- que eran muy débiles para intentar ejercer el poder municipal, incluso en grandes ciudades industriales donde tenían que estar subordinados a intereses privados, fuesen propietarios o compañías de servicios. Este hecho provocó que se dejara en manos de empresas privadas los servicios municipales y se otorgaran concesiones para solucionar este problema del abastecimiento.

El análisis histórico nos permite afirmar que el modelo privatizador fracasó porque, entre otras cosas, las empresas privadas encarecieron de manera especulativa el precio del recurso y se negaban a realizar inversiones que facilitaran el acceso de agua a la mayoría de la población. Esta situación hizo que a partir de los años veinte del siglo XX los municipios fueran recuperando el servicio y solamente pervivieron empresas en lugares puntuales como Barcelona. Puede decirse que la privatización del agua fue un fracaso y en 1950 casi todos los servicios de agua fueron municipalizados.

El abastecimiento de aguas a la población ha constituido desde entonces un típico servicio público municipal, hoy además calificado como servicio esencial, reservado ex lege y de establecimiento y prestación obligatorios para todos los municipios ${ }^{13}$. No obstante, lejos de cerrarse el debate sobre la privatización, desde mediados de los años ochenta la legislación española permite a las entidades locales externalizar el servicio; así, el ya mencionado canon concesional se ha terminado convirtiendo en uno de los ejes de la expansión de la gestión privada del servicio.

En 1996, el 63\% de la población española estaba abastecida por alguna forma de gestión pública y el $37 \%$ a través de un sistema de gestión privada. En 2006, las formas de gestión privadas ya gestionaban el servicio al $48 \%$ de la población. A partir de esa fecha, los porcentajes se invierten: $47 \%$ gestión pública y $53 \%$ gestión privada. En la actualidad el $55 \%$ de la población es abastecida por alguna forma de gestión privada y dicha cifra podría aumentar en los próximos años si se consuman los procesos de privatización pendientes. La Tabla 1 muestra algunos datos de las empresas públicas locales del sector en España.

Tabla 1. Las empresas públicas locales gestoras del ciclo urbano del agua en cifras

\begin{tabular}{|l|r|c|}
\hline \multicolumn{2}{|l|}{} & $\begin{array}{c}\text { Porcentaje respecto } \\
\text { al total de EPL }\end{array}$ \\
\hline Empresas & 104 & $9,2 \%$ \\
\hline Empleados & 10.671 & $14,2 \%$ \\
\hline Ingresos & $1.495 .358 .106 €$ & $18,3 \%$ \\
\hline Balance & $5.079 .505 .555 €$ & $17,2 \%$ \\
\hline Resultados & $48.254 .122 €$ & - \\
\hline
\end{tabular}

* Empresas Públicas Locales

Fuente: Elaboración propia a partir de ELIGE, 2012.

13 Arts. 26.1.a y 86.3 de la ley 7/1985, de 2 de abril, reguladora de las Bases del Régimen Local. 
Gráfico 1. Impacto de la Ley 27/2013 sobre el número de empresas públicas locales gestoras del ciclo urbano del agua

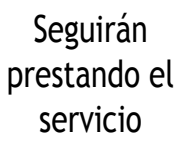

(66)

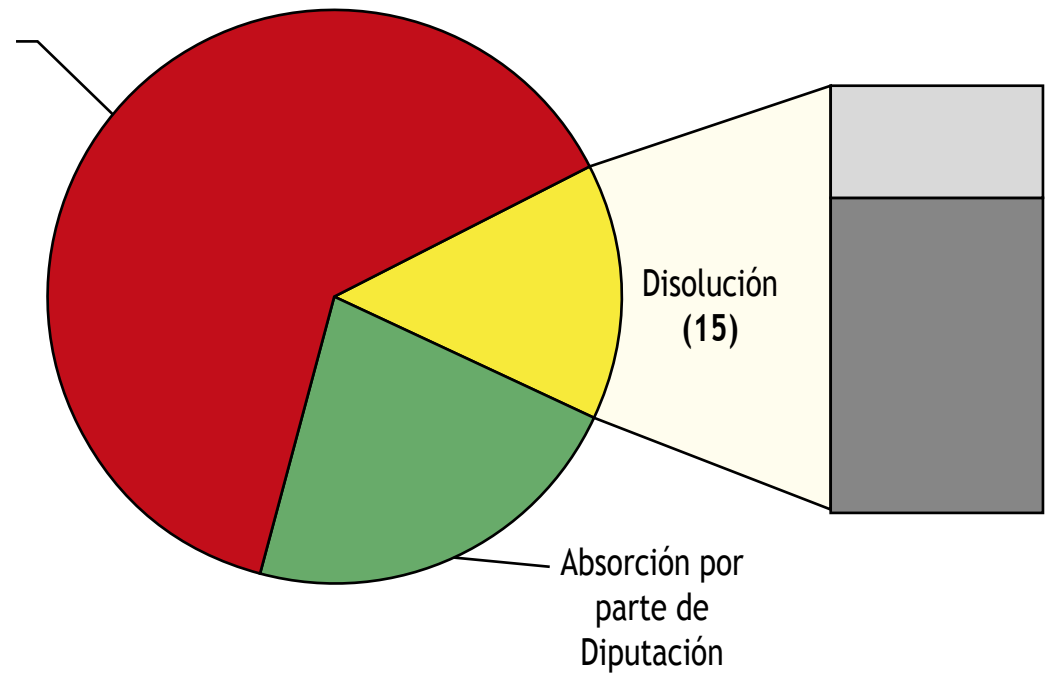

Por ser de segundo nivel

Por desequilibrio económico financiero no ajustable
Fuente: Elaboración propia a partir de ELIGE, 2012.

Para conseguir que el negocio del agua fuera aún más seguro el lobby privado consiguió en el año 2011, a través de la denominada Ley de Economía Sostenible, que el agua se rigiera a través de un precio privado, es decir, a través de una tarifa y no de una tasa, en el caso de que la entidad que gestiona el servicio público sea una sociedad privada municipal 0 una empresa privada ${ }^{14}$. Lo que supone, en última instancia, mermar las garantías de los ciudadanos en el acceso al recurso; por ejemplo, facilitando los cortes por impago.

Con la crisis en pleno auge, y con el argumento de eliminar duplicidades y racionalizar costes, el gobierno conservador aprobó en diciembre del 2013 la ley $27 / 2013^{15}$ (ver Anexo II) que, entre otras cosas, establece el criterio de coste estándar del servicio, cuya metodología de formulación se encuentra en desarro$10^{16}$; este criterio servirá para favorecer, cuando no forzar, la privatización de servicios ${ }^{17}$. De hecho, de las 104 empresas públicas

14 En efecto, el primer paso para este intento de deslegalización se produjo con la supresión del segundo párrafo del artículo 2.2.a) de la ley 58/2003, de 17 de septiembre, General Tributaria, tras la reforma de esta última llevada a cabo por la ley 2/2011, de 4 de marzo, de Economía Sostenible. El segundo paso tuvo lugar con el informe de 26 de julio de 2011 de la Dirección General de Tributos del Ministerio de Economía y Hacienda, solicitado por AEAS.

15 Ley 27/2013, de 27 de diciembre, de racionalización y sostenibilidad de la Administración Local. El preámbulo de esta norma indica claramente entre sus objetivos favorecer la iniciativa económica privada.

16 La determinación del coste estándar del servicio no es una cuestión sencilla, ni puede aplicarse un solo coste estándar para todos los abastecimientos. Un cálculo riguroso de este coste estándar debería tomar en cuenta, al menos, las economías de escala, las economías de alcance, las economías de densidad de usuarios, las economías de densidad de producto, los factores de entorno y la calidad del servicio.

17 La ley/2013 establece que cuando el coste efectivo por la prestación del servicio en municipios de menos de 20.000 habitantes sea superior al coste estándar fijado reglamentariamente las Diputaciones asumirán el ejercicio de las competencias. Las Diputaciones carecen de capacidad para gestionar directamente de agua que actualmente existen en España 38 corren serio riesgo de desaparecer o ser privatizadas (Gráfico 1).

Sin embargo, el agua en nuestro país, como en la mayoría de las culturas mediterráneas, sigue manteniendo un fuerte valor simbólico, un significado de fuente de vida. Este valor simbólico, no obstante, no se ha traducido en resistencia organizada al proceso de privatización hasta fechas muy recientes.

\section{CRISIS ECONÓMICA Y RESISTENCIA CIUDADANA}

El sistema económico-político neoliberal imperante ha dejado al descubierto el interés prioritario en privatizar todos aquellos sistemas colectivos que, como los servicios públicos urbanos de agua y saneamiento, han sido fórmulas tradicionales de protección social y garantía de accesibilidad. Los fracasos vividos al inicio de la década en Latinoamérica -en buena medida, consecuencia de las protestas ciudadanas - han reorientado la estrategia de las multinacionales del agua hacia los denominados mercados maduros; mercados donde se minimizan los riesgos dado que los recibos del agua tienen una alta garantía de pago -más del 97\%-. España no ha quedado al margen de esta tendencia privatizadora.

Estas privatizaciones impiden que se destinen los bienes al servicio de las necesidades sociales, agravadas como consecuencia de la actual crisis económica, y los sitúan al margen de los mecanismos de control democrático. Este es el principal motivo que está llevando a la ciudadanía a tomar conciencia social sobre el agua como bien común. Por tanto, el actual proceso de privatización de la gestión del agua también está provocando un

los abastecimientos, y este traspaso competencial puede hacer más atractiva para el sector privado la gestión de un conjunto de municipios. 
movimiento social de resistencia frente a la mercantilización. Las estrategias de la sociedad civil se pueden agrupar en acciones jurídico-institucionales para ralentizar el proceso de privatización y de movilización ciudadana. Así, en España, desde los inicios de la actual crisis económica ha habido fuertes movimientos ciudadanos en defensa del agua como bien común.

En diciembre de 2008, los vecinos de Avilés (Asturias) consiguieron crear una de las plataformas más activas del país contra la privatización del agua. Constituida por veintiún colectivos, esta plataforma consiguió casi veinte mil firmas -en un municipio de 83.000 habitantes- para exigir que la gestión del agua se decidiera por referéndum. Estas movilizaciones no impidieron que el $1 .^{\circ}$ de enero de 2010 comenzara a operar una nueva sociedad participada en un $74 \%$ por Aquagest -grupo AGBAR/Suez-y en un $26 \%$ por el Ayuntamiento, que recibió un canon de 37,5 millones de euros como compensación. Actualmente, Aquagest -hoy AQUADOMestá bajo sospecha; sus máximos responsables están imputados y sus interlocutores políticos también, entre ellos, siete alcaldes y/o ex alcaldes, como los de Orense, Santiago de Compostela, Lugo o Corvera (Asturias). Sin ir más lejos, el ex alcalde de la vecina Corvera está imputado por cohecho y blanqueo de capitales.

A inicios del 2012, y bajo el lema "Se escribe AGUA, se lee DEMOCRACIA", se creó la Red Agua Pública. Esta heterogénea red estatal ${ }^{18}$ ha servido, a veces con muchos problemas, para coordinar a todos los movimientos españoles contra la privatización de la gestión del agua, intercambiar experiencias y colaborar en las estrategias de lucha. Desde entonces han sido notorias las actuaciones llevadas a cabo en Cataluña a través de la plataforma "Aigua és Vida", en Andalucía - Jerez, El Puerto de Santa María y Priego de Córdoba - a través de la Marea Azul del Sur, en Candeleda (Ávila), Ermua (Vizcaya) o en la ciudad de Murcia.

A continuación, analizaremos con más detalle dos procesos de resistencia ciudadana frente a la privatización del servicio de agua: el intento de privatización del Canal de Isabel II (Madrid) y la privatización del servicio de aguas de Alcázar de San Juan (Ciudad Real).

\section{El intento de privatización del Canal de Isabel II}

Los intentos de salvar a Bankia ${ }^{19}$ y el alto nivel de endeudamiento que sostiene la Comunidad de Madrid hizo que la Asamblea autonómica, a través de la ley $3 / 2008$ de 29 de diciembre, sobre Medidas Fiscales y Administrativas, aprobara la privatización del Canal de Isabel II (CYII) con los únicos votos a favor del Partido Popular -en 2010 el CYII obtuvo unos beneficios de 114 millones

18 La red estuvo inicialmente compuesta por la Asociación Española de Operadores Públicos de Abastecimiento y Saneamiento (AEOPAS), la Asamblea PazFama-Vistabella (Murcia), la Coordinadora en Defensa de la Gestión Pública del Agua en Jerez, Ecologistas en Acción, la Federación española de Ingeniería Sin Fronteras, la Plataforma "Aigua és vida", la Plataforma contra la Privatización del Canal de Isabel II y la Red Andaluza de la Nueva Cultura del Agua. Con el tiempo, se han ido incorporando la mayoría de los movimientos anti-privatización que se han ido constituyendo en el Estado.

19 Caja Madrid trató de amañar la privatización del Canal de Isabel II con Blesa al frente. Disponible en: http://www.lasexta.com/noticias/economia/cajamadrid-trato-amanar-privatiza-cion-canal-isabel-blesa-frente_2013122600149. html. de euros-. No obstante, se encontró con la oposición inicial del entonces alcalde de la capital y también se posicionó en contra la Confederación Hidrográfica del Tajo, organismo estatal que regula el agua en la región, por entonces en manos socialistas. A partir de ese momento se inició un laborioso -y opaco- proceso intensivo de corporativización ${ }^{20}$ de la empresa en pro de su privatización: reparto de la propiedad entre los ayuntamientos que lo conforman y creación de la Sociedad Anónima Canal de Isabel II Gestión, participada en un $82,4 \%$ por el ente público y el $17,6 \%$ restante por los 111 municipios presentes en el accionariado. Esta fórmula permite, entre otras cosas, repartir dividendos y acudir a concursos para gestionar el agua de otras ciudades como si se tratase de una empresa privada ${ }^{21}$.

Para oponerse a esta iniciativa se constituyó la Plataforma contra la privatización del Canal de Isabel II (PCPCYII). Se trata de un movimiento social urbano en el que participan organizaciones sociales, sindicatos, grupos ecologistas, partidos políticos y ciudadanos pertenecientes al 15-M. En este sentido, no es simplemente una organización que se resiste a la privatización del agua sino que intenta cambiar el modelo de gestión a partir de anhelos más profundos ${ }^{22}$. La incorporación del 15-M a la PCPCYII posibilitó que el movimiento del agua tuviera capacidad de hibridación con otros colectivos sociales -las plataformas de defensa de la sanidad y la educación públicas- que también defienden "un derecho de ciudad", remodelar la urbe de acuerdo con una imagen diferente de la promovida por los promotores inmobiliarios respaldados por el capital financiero, el corporativo y un aparato de Estado cada vez más imbuido por una lógica estrictamente empresarial.

El 15-M también fue crucial a la hora de difundir el mensaje ya que gracias a la existencia de múltiples asambleas en los barrios y municipios de la Comunidad de Madrid, la ciudadanía accedió e incorporó como propias las reivindicaciones de la PCPCYII contra la privatización del CYII. El apoyo al movimiento creció significativamente con personas de todos los estratos de la población y, especialmente, jóvenes que hasta el momento no se habían movilizado. Este fenómeno se ha repetido en otros movimientos de defensa del agua del Estado -Jerez, Candeleda 0 Murcia-.

Entre las acciones de movilización ciudadana cabe destacar la organización, en marzo del 2012, de una consulta popular por el agua para que la ciudadanía de la región de Madrid pudiera pronunciarse sobre el intento privatizador del CYII. La PCPCYII organizó más de trescientas mesas que se repartieron por toda la Comunidad. Votaron más de ciento ochenta mil personas y el $99 \%$ dijo estar de acuerdo con el carácter público de la empresa de aguas. La consulta fue un éxito ya que logró evidenciar la capaci-

20 El gobierno corporativo es la interacción de la gerencia, los miembros de la junta directiva y los propietarios de una empresa para dirigir y controlar la firma y asegurar que todos los aportantes a la estructura de capital -propietarios y acreedores financieros- reciban la parte que les corresponde de los ingresos y activos de la empresa. En las empresas públicas se suele dar la corporativización cuando las empresas actúan solo atendiendo a su capacidad de crear valor económico, que no necesariamente tiene que ser revertido en la calidad del servicio.

21 El Canal subirá el agua de Lanzarote para pagar la deuda. Disponible en: http://ccaa.elpais.com/ccaa/2013/07/10/madrid/1373490240_133476.html.

22 Harvey, 2008. 
dad de acción y movilización de la sociedad civil. No obstante, la intención de los promotores de la consulta era animar al Gobierno autonómico a llevar a cabo un referéndum sobre la cuestión para conocer la opinión de la ciudadanía. Finalmente, ni siquiera el Parlamento regional lo discutió.

Paralelamente a la movilización, la PCPCYII desarrolló una serie de vías jurídicas e institucionales para socavar el proceso de privatización. Y este camino fue decisivo, ya que el 15 de mayo del 2012 el Tribunal Constitucional admitió a trámite un recurso de inconstitucionalidad de más de cincuenta senadores socialistas contra la privatización del CYll; el día 29 del mismo mes, la entonces presidenta de la Comunidad de Madrid, Esperanza Aguirre, frenaba la privatización para "no malvenderlo". La Plataforma sigue trabajando contra el actual proceso de corporativización del CYII y se ha convertido en un referente de la lucha a nivel nacional e incluso europeo.

\section{La privatización del servicio en Alcázar de San Juan}

El movimiento social que hasta la fecha ha conseguido comparativamente mayores movilizaciones y logros es el de Alcázar de San Juan (Ciudad Real), una población de 32.000 habitantes. La Plataforma contra la Privatización de Aguas de Alcázar (PCPAA) se constituyó en el verano de 2013 cuando se conoció que el equipo de gobierno del Ayuntamiento, formado por una coalición del Partido Popular (PP) y el grupo independiente Ciudadanos por Alcázar (UCIN) -fundado por un ex miembro del PSOE-, había convocado un pleno el día 19 de julio de 2013, aprovechando el verano y las vacaciones de muchos de los ciudadanos de Alcázar, con la propuesta de iniciar el estudio para un cambio en la gestión del agua y de tener cerrado el proceso el 1. ${ }^{\circ}$ de enero de 2014.

Desde el principio, la estrategia de los ciudadanos contrarios a la intención municipal fue desplegar una campaña de información y educación que se centró en analizar las implicaciones de la operación de privatización propuesta por el equipo de gobierno y desmentir las noticias que suministraba la coalición del PP y los independientes. Paralelamente a esta campaña se creó una estructura jurídica capaz de defender legalmente los intereses de los ciudadanos y ralentizar, en lo posible, el proceso de privatización.

Como acciones concretas pueden destacarse la elaboración de un tríptico con la información del proceso repartido por miembros de la PCPAA en toda la ciudad; charlas informativas a las asociaciones y agrupaciones que lo solicitaron; mesas informativas en los principales espacios sociales del municipio; recogida de firmas -11.000 en ocho meses-; concentraciones semanales y manifestaciones a las que empezaron acudiendo 700 personas y en las que terminaron asistiendo más de dos mil; asistencia a todos los plenos municipales para demostrar la oposición al proceso y preguntar pacíficamente sobre la privatización; asambleas semanales abiertas y participativas en las que cualquier asistente podía proponer nuevas acciones; y conferencias de prensa donde se informaba de los acuerdos adoptados en la asamblea.

Sin duda, la acción con mayor repercusión mediática y que convirtió al de Alcázar de San Juan en referencia de muchos movi- mientos consistió en un encierro de tres días en su Ayuntamiento para conseguir que el Gobierno municipal organizara una consulta popular entre los 32.380 habitantes. Durante este tiempo, el pueblo se concentró en apoyo de los encerrados. El respaldo al movimiento creció y las manifestaciones paralelas atrajeron a personas que raras veces se habían visto en una acción conjunta. De hecho, el abandono del encierro se hizo coincidir con una manifestación de más de tres mil quinientas personas en la plaza principal. "El pueblo entero ha estado aquí en la plaza, no recordábamos nada asi”, manifestó Juan Garrido, portavoz de la PCPAA. Sin embargo, ese mismo día, el pleno del Ayuntamiento rechazó la iniciativa presentada por la plataforma de llevar a referéndum la privatización de la gestión.

A pesar de esto y de las trabas de la Subdelegación del Gobierno, la PCPAA organizó una consulta que consiguió que 7.724 alcazareños expresaran su opinión. Un total de 7.627 vecinos se opuso al proceso de privatización y se evidenció que este tipo de ejercicios democráticos se pueden realizar de forma autónoma con garantías - la PCPAA creó una aplicación informática para poder controlar la votación e impedir que algunas personas pudieran votar más de una vez-. En definitiva, la PCPAA impulsó una campaña educativa y didáctica para que cada vecino, libremente, decidiese su postura, pero con información veraz, comprensible y transmitida eficazmente. Estas fueron las claves de la movilización y del éxito.

Destacando una vez más que la importancia del caso Alcázar de San Juan ha consistido fundamentalmente en haber podido movilizar a la mayoría de la ciudadanía, no es menos cierto que, como en el caso de Madrid, la PCPAA consiguió parar, en dos ocasiones, el proceso de privatización gracias a un hito jurídico: la resolución 299/2014 del Tribunal Administrativo Central de Recursos Contractuales de fecha 11 de abril, por la que, al declarar nulos de pleno derecho dos aspectos del Pliego de Cláusulas Administrativas Particulares, se anulaba el procedimiento de licitación, incluidos los actos preparatorios. No obstante, a pesar de los encierros, manifestaciones, consultas y actuaciones judiciales el proceso de privatización se consumó en septiembre de 2014.

El Ayuntamiento de Alcázar de San Juan firmó con Aqualia S. A. el contrato mediante el cual esta última adquiere el 52,38\% del capital social de Aguas de Alcázar Empresa Municipal S. A. y constituye junto al Ayuntamiento una nueva empresa a la que se concede la gestión del servicio del ciclo integral del agua en el municipio durante 25 años. Aqualia adquiere la mayoría de las acciones por un total de $66.111,32$ euros, más 1.075.811,66 euros de abono de una prima de emisión al Ayuntamiento cuyo destino último se desconoce. Además Aqualia aporta a la nueva sociedad un préstamo por valor de 6.525 .876 euros, que tendrá que reembolsar en diez años la empresa mixta junto a unos intereses anuales del 4\%, para financiar el pago de la deuda que tiene contraída Aguas de Alcázar con el propio Ayuntamiento de Alcázar de San Juan, su propietario hasta ahora. Es decir, que el dinero va a parar al Ayuntamiento.

También se incluye un compromiso de inversión de 4,5 millones que la nueva empresa mixta deberá destinar a obras de naturaleza hidráulica durante los 25 años que dure la concesión. 
Bien entendido que estas obras no las financiará el socio privado a su costa sino la sociedad mixta con sus recursos, obtenidos de la recaudación del servicio 0 , en su caso, acudiendo a préstamos reembolsables. De este modo, si la empresa tiene que hacer frente a obras y no tiene dinero en caja, no lo pondrá la empresa, sino que acudirán antes a un préstamo -que lógicamente habrá que devolver de nuevo pagando más intereses-. El negocio es seguro ya que la aportación inicial del socio privado será de 2,8 millones aproximadamente, sumando coste de acciones y prima de emisión junto a anticipo de canon. Los estatutos de la nueva sociedad prevén que anualmente se irá formando un fondo, con los ingresos de explotación, para que al acabar el plazo de concesión se devuelva al socio privado lo que desembolsó por las acciones.

El canon inicial, anticipado por Aqualia, lo recuperará en unos ocho años porque se ha previsto como un coste más entre los gastos de explotación anuales de la nueva sociedad mixta. El servicio de los intereses del préstamo que aporta Aqualia a la sociedad y su amortización correrán por cuenta de la sociedad mixta durante 10 años y del resto de la aportación el socio privado se resarcirá como máximo en tres años con los beneficios de explotación que le correspondan en relación a su capital social y, además, con el ingreso que tiene garantizado, un $8 \%$ de la facturación anual, por su know-how. Todo ello suponiendo que el volumen de facturación o las tarifas permanezcan invariables, lo cual parece improbable cuando el propio Ayuntamiento y el socio privado se llevan un $13 \%$ de la facturación y, por lo tanto, tienen interés en su incremento.

\section{Conclusiones}

Sólo una correcta armonización entre el derecho y la movilización popular puede dar resultados positivos frente a los procesos privatizadores en este sector, puesto que este tipo de procesos no se paralizan tan solo con acciones populares. Además, para reforzar el papel del agua como bien común es necesaria una estrategia que posibilite cambios legislativos a nivel estatal. En este sentido, si la legislación simplemente prohibiera -como en la mayoría de los países europeos- que los cánones concesionales se utilicen para fines distintos de la mejora de las infraestructuras hidráulicas, los procesos de privatización serían en España algo muy residual. No hacer esto es fomentar una burbuja hídrica basada en la utilización de la tarifa del agua como mecanismo de recaudación no transparente para financiar a los municipios y cuyo resultado, no muy lejano, será una ausencia de inversión en la gestión del ciclo urbano que conducirá a su insostenibilidad y, quizás, a su posterior rescate público pagado por todos.

En España las soluciones propuestas al problema del agua se han dirigido a la oferta de este recurso, sin apenas ocuparse de su gestión. El énfasis de la nueva política de aguas debe de ponerse en la gestión pública participativa, sin ánimo de lucro, como servicios de interés general. Para ello, es necesario establecer un amplio consenso a través de un pacto por el agua pública en el que se definan y acuerden los fundamentos y las reglas básicas del modelo público - transparencia, rendición de cuentas, participación social-, que frene el incipiente proceso de corporativización que también amenaza al modelo público y que conduzcan hacia el objetivo final de la sostenibilidad económica, social y ambiental.

Recientemente, AEOPAS junto a una docena de organizaciones vecinales, de consumidores, ecologistas y científicas -Fundación Nueva Cultura del Agua - y de otros ámbitos han presentado un pacto por el agua pública, que pretende blindar este recurso ante las normas del mercado y las presiones privatizadoras. La iniciativa (\#iniciativagua2015), que defiende el carácter del suministro de agua como un derecho humano -en línea con la declaración de Naciones Unidas y con la primera iniciativa ciudadana promovida en la UE- intenta prohibir los cortes de suministro; asegurar un mínimo de entre 60 y 100 litros por persona y día en caso de impago justificado; eliminar la participación de la empresa privada; garantizar tarifas sostenibles; asegurar que el dinero procedente del agua se reinvierta solo en este ámbito; aumentar el control social sobre los recursos; que la gestión del suministro también sea un elemento de creación de empleo; e incluso promover el consumo del agua de grifo frente al agua embotellada. Se trata de elaborar un nuevo modelo de gestión pública, democrática, transparente y participativa. La iniciativa plantea cambios estructurales - por ejemplo, se recoge la implementación de un órgano fiscalizador que cuente con colectivos sociales-, un reto complejo y al mismo tiempo fascinante.

\section{Anexo I. El Caso de Jerez: Cómo sacar dinero de la pobreza}

Ducharse o beber del grifo no es un derecho en España, es un servicio; cuesta dinero y se puede cortar. No existe una cifra nacional de afectados por cortes de suministro porque el abastecimiento de agua es un servicio local y cada municipio lo gestiona autónomamente. La Asociación Española de Operadores Públicos de Abastecimiento y Saneamiento (AEOPAS) calcula que se tramitan al año más de quinientos mil avisos de corte, un $30 \%$ más que hace cuatro años.

Fernando Morcillo, presidente de la Asociación Española de Abastecimientos de Agua y Saneamiento (AEAS), patronal del sector, afirmó recientemente no haber detectado tantas incidencias como se denuncian: "En cualquier caso, los servicios de aguas cuentan con elementos de acción social para tratar estos temas mediante la reducción de la cuota y existe un procedimiento reglado con advertencias y plazos de regularización antes de llegar a un corte que decide siempre la Administración local, no el operador"23. Un procedimiento, por tanto, que facilita que los operadores privados conviertan el corte del suministro en una virtud garantizándose, gracias a los fondos municipales (aproximadamente un $4 \%$ de la factura), el $100 \%$ del cobro de las tarifas del servicio.

En Jerez, el gobierno local del Partido Popular adjudicó en 2013 la gestión del servicio municipal de aguas a la empresa Aqualia, que creó para este cometido la sociedad AquaJerez. La concesión tiene una duración de 25 años, con un canon concesional de 80 millones de euros fraccionado en dos pagos. A principios de 2014 esta empresa inició una campaña para cortar el sumi-

$23 \mathrm{http}$ ///sociedad.elpais.com/sociedad/2014/03/21/actualidad/1395399747_606415.html. 
nistro a los usuarios que tenían facturas impagadas. Los cortes afectaron a más de doscientos hogares jerezanos. La alcaldesa, María José García-Pelayo, en plena crisis por la oleada de cortes de abastecimiento emprendida por Aqualia, declaró: "Ahora mismo hay en Jerez 7.183 contratantes con problemas para pagar el recibo del agua"24.

Ante las protestas ciudadanas el gobierno municipal reaccionó cambiando la ordenanza del agua que "recoge la posibilidad de bonificación en los supuestos de cuotas de suministros de bloques colectivos o comunitarios; y asimismo establece la concesión de estos beneficios de oficio durante todo el año por motivos excepcionales, con un informe de los servicios sociales, para aquellas personas en situación económica especialmente desfavorecida; es el caso de estas ayudas compensatorias que han experimentado un notable incremento por el compromiso del gobierno municipal con las políticas sociales"25, según ha subrayado recientemente la delegada de Bienestar Social, Igualdad y Salud del ayuntamiento jerezano. En los cuatro primeros meses de 2014 ya se han concedido 1.665 ayudas de compensación, es decir, 1.367 más que en el mismo periodo de 2013 porque entonces se concedieron 289. Dichas ayudas han crecido un $476 \%$ $\mathrm{y}$, evidentemente, es algo que tiene que ver con el hecho de que la gestión del ciclo integral del agua esté ahora en manos de una empresa privada que, lógicamente, lo que busca es hacer negocio y maximizar sus beneficios.

La situación de emergencia social que sufre la ciudad con mayor tasa de paro (41\%) de la zona euro también ha provocado, según el Ayuntamiento, que junto a la asistencia en el suministro de un bien esencial, como el agua, las ayudas en metálico y alimentos que conceden los servicios municipales hayan experimentado un enorme incremento. En el primer cuatrimestre se han concedido 4.184 ayudas, 1.493 más que en el mismo periodo de 2013, año en el que se otorgaron 2.692. Esto supone un aumento del 55,42\%. Poco a poco, los avisos de corte del suministro de agua aumentarán; los fondos sociales disminuirán en uno de los municipios que sostiene mayor deuda y, mientras tanto, el negocio del agua habrá logrado disminuir aún más los riesgos, ya que la operadora privada ha incrementado su garantía de cobro, que se aproxima al $100 \%$.

\section{Anexo II. Reforma de La aDMINISTRACIÓn local y MERCANTILIZACIÓN DE LOS SERVICIOS URBANOS DE AGUA}

La ley 27/2013, de 27 de diciembre, de racionalización y sostenibilidad de la Administración Local expresa en su preámbulo cuatro objetivos:

a) Clarificar las competencias municipales para evitar duplicidades con las competencias de otras administraciones. Sin embargo, no parece muy coherente este objetivo con la

24 http://www.europapress.es/andalucia/cadiz-00351/noticia-garcia-pelayo-defiende-gestion-aqualia-critica-rigidez-normativa-aguas-junta-20140125134030.html

25 http://www.jerez.es/nc/webs_municipales/prensa/noticia_simple_ prensa/?tx_ttnews\%5Btt_news\%5D $=20656 \mathrm{\& t}$ _ttnews\%5BbackPid\%5D $=13976 \mathrm{dtCHa}$ sh $=806 a 8 a 6 b 90 a 55 e 5 f 6391$ c87fc6c041e9 propia naturaleza de los servicios urbanos de agua. De una parte, la propia Ley reconoce como competencia propia del municipio el abastecimiento de agua potable a domicilio y la evacuación y tratamiento de aguas residuales. Por otra parte, el legislador no toma en consideración que el servicio urbano de aguas es un monopolio natura ${ }^{26}$, puesto que se trata de un sector muy intensivo en capital con elevados costes fijos, de modo que las duplicidades de redes son ineficientes $^{27}$. Por tanto, ¿a qué duplicidades se refiere la norma cuando se aplica al sector del agua urbana?

b) Favorecer la iniciativa económica privada evitando intervenciones administrativas desproporcionadas. Sin embargo, el legislador parece ignorar la elevada concentración del sector privado que participa en esta industria en España ${ }^{28}$.

c) Garantizar un control financiero y presupuestario más riguroso. Sin embargo, la norma no considera la desigual situación financiera de los municipios; de hecho, tiene efectos más acentuados sobre la gestión del agua en municipios de menos de 20.000 habitantes, donde la situación financiera está más saneada. Los municipios de menos de 20.000 habitantes representan el $95 \%$ del total de municipios españoles, donde habita el $32 \%$ de la población, pero su deuda viva solo representa el 19\% de la deuda municipal; el importe de la deuda viva por habitante para los municipios de menos de 20.000 habitantes era de 442,4 euros a 31 de diciembre de 2012, mientras que en los municipios de más de 20.000 habitantes esa cifra es prácticamente el doble, alcanzando los 885,8 euros por habitante ${ }^{29}$.

d) Racionalizar la estructura organizativa de la Administración Local de acuerdo a los principios de eficiencia, estabilidad y sostenibilidad financiera. Sin embargo, la privatización de la gestión de los servicios urbanos de agua no promueve necesariamente la eficiencia ${ }^{30} \mathrm{y}$, en general, la norma no se preocupa del verdadero estado de los abastecimientos, ni de la prestación de un servicio de calidad.

Los efectos de esta norma sobre los servicios de agua urbanos dependen del número de habitantes del municipio, más concretamente, si este es inferior o superior a 20.000 habitantes.

a) Municipios de menos de 20.000 habitantes. Cuando el coste efectivo por la prestación del servicio en el ámbito municipal sea superior al coste estándar fijado reglamentariamente las Diputaciones asumirán el ejercicio de las competencias. Por tanto, la cesión de la prestación del servicio depende de la forma de determinación del coste estándar.

En caso de cesión, la potestad para la imposición de tasas y precios públicos por la prestación del servicio queda en manos de las Diputaciones. Sin embargo, las Diputaciones no asumen como propias las operaciones de endeudamiento

\footnotetext{
26 Sepälä, Hukka y Katko, 2001.

27 Bishop, Kay, y Mayer, 1994.

28 Warner y Bel, 2008.

29 Ministerio de Hacienda. Disponible en: http://www.minhap.gob.es/ESES/ESTADISTICA\% 20E\%20INFORMES/Paginas/estadisticaseinformes.aspx.

30 González-Gómez, y García-Rubio, 2008.
} 
que el municipio haya contraído como consecuencia de un déficit en el servicio.

Por el contrario, si pasados cinco años de la cesión de la prestación del servicio a la Diputación el municipio recuperara el ejercicio de las competencias, el municipio debe asumir las obligaciones existentes en ese momento.

Por último, la cesión del servicio a las Diputaciones hace más atractiva para la empresa privada la participación en el sector, al permitir la privatización simultánea de un conjunto de servicios urbanos de agua.

b) Municipios de más de 20.000 habitantes. En estos municipios la norma introduce una fuerte asimetría en la elección de la forma de gestión, que favorece los procesos privatizadores. Solo puede hacerse uso de entidades públicas empresariales locales y de sociedades mercantiles locales cuando quede acreditado mediante memoria justificativa que resultan más sostenibles y eficientes que la gestión por la propia entidad local o por un organismo autónomo local. Sin embargo, la elección de cualquiera de las formas de gestión que implique la privatización del servicio no tiene ninguna exigencia.

\section{BibLIOGRAFíA}

AEAS-AGA, 2006: Suministro de agua potable y saneamiento en España 2006. Madrid, Asociación Española de Abastecimientos de Agua y Saneamiento-Asociación Española de Empresas Gestoras de los Servicios de Agua a Poblaciones.

AEAS, 2012: Suministro de agua potable y saneamiento en España 2012. Madrid, Asociación Española de Abastecimientos de Agua y Saneamiento.

Bel, G. y Fageda, X. 2007: "Why do local governments privatise public services? A survey of empirical studies", en Local Government Studies, 33, 4, 517-534.

Bel, G. y Fageda, X. 2009: "Factors explaining local privatization: a meta-regression analysis", en Public Choice, 139, 1, 105-119.

Bishop, M., Kay, J. y Mayer, C. 1994: Privatization and Economic Performance. New York, Oxford University Press.

Biswas, A. K. 2006: "Water Management for Major Urban Centres”, en Water Resources Development, 22, 2, 183-197.

ELIGE, 2012: “Directorio de Empresas Públicas Locales 2012”. Sevilla, Red de Empresas Locales de Interés General (ELIGE).
García-Rubio, M. A., González-Gómez, F. y Guardiola, J. 2009: “La gestión del servicio de abastecimiento de agua en las ciudades. ¿Empresa pública o privada?". Granada. Comunicación presentada al XVI Encuentro de Economía Pública, 5 y 6 de febrero de 2009.

González-Gómez, F. y García-Rubio, M. A. 2008: "Efficiency in the management of urban water services. What have we learned after four decades of research?", en Hacienda Pública Española. Revista de Economía Pública, 185, 2, 39-67.

González-Gómez, F., García-Rubio, M. A. y Guardiola, J. 2012: "Urban Water Service Policies and Management in Spain: Pending Issues", en International Journal of Water Resources Development, 28, 1, 89-106.

González-Gómez, F., García-Rubio, M. A. y González-Martínez, J. 2014: "Beyond the public-private controversy in urban water management in Spain", en Utilities Policy, 31, 1-9.

Harvey, D. 2008: "The right to the city", en New Left Review, 53 (disponible en: http://newleftreview.org/ll/53/david-harvey-theright-to-the-city).

Matés Barco, J. M. 2008: "Empresas, sociedad y servicios públicos: del Estado prestador al Estado regulador", en Revista Empresa y Humanismo, XI, 1/08, 187-230.

OECD, 2004: "Competition and Regulation in the Water Sector". Paris, DAFFE/COMP, 20.

Pigeon, M. 2013: "Une eau publique pour Paris: Simbolismo y éxito en el corazón del agua privada", en Pigeon, M., McDonald, D. A., Hoedeman, 0. y Kishimoto, S. (eds.): Remunicipalización: El retorno del agua a manos públicas. Amsterdam, Transnational Institute, 28-49.

Sepälä, 0. T., Hukka, J. J. y Katko, T. S. 2001: "Public-Private Partnerships in Water and Sewerage Services. Privatization for Profit or Improvement of Service and Performance?", en Public Works Management \& Policy, 6, 1, 42-58.

Tribunal de Cuentas, 2013: "Informe de fiscalización del Sector Público Local, ejercicio 2011", n. ${ }^{\circ}$ 1010. Madrid, Tribunal de Cuentas (disponible en: http:// www.tcu.es/repositorio/fd3654bc-3504-4181ade563e8a0dea5c2//1010.pdf).

UrbanWater FP7 Project, 2014: The European Water Market Analysis. UrbanWater Consortium. Grant Agreement: 318602 (disponible en: http://urbanwater-ict.eu/wp-content/uploads/2014/08/URBANWATER-D1.1-The-European-Water-Market-Analysis.pdf).

Varis, O., Biswas, A. K., Tortajada, C. y Lundqvist, J. 2006: "Megacities and Water Management", en International Journal of Water Resources Development, 22, 2, 377-394.

Warner, M. E. y Bel, G. 2008: “Competition or monopoly? Comparing privatization of local public services in the US and Spain", en Public Administration, 86, 3, 723-735. 